\title{
RFID Technology for Human Implant Devices
}

\section{Technologie RFID pour implants dans le corps humain}

\author{
Hervé Aubert \\ Laboratoire d'Analyse et d'Architecture des Systèmes (LAAS) - CNRS \\ and \\ University of Toulouse: INP, UPS, INSA, ISAE \\ 7 Avenue du colonel Roche, Toulouse, France - email : aubert@enseeiht.fr
}

\begin{abstract}
This paper presents an overview on Radio Frequency Identification (RFID) technology for human implants and investigates the technological feasibility of such implants for locating and tracking persons or for remotely controlling human biological functions. Published results on the miniaturization of implantable passive RFID devices are reported as well as a discussion on the choice of the transmission frequency in wireless communication between passive RFID device implanted inside human body and an off-body interrogator. The two techniques (i.e., inductive coupling and electromagnetic coupling) currently used for wirelessly supplying power to and read data from passive implantable RFID device are described and some documented biomedical and therapeutic applications of human RFID-implant devices are finally reported.
\end{abstract}

Résumé - Cet article dresse un état de l'art sur la technologie des puces RFID implantées dans le corps humain. Il explore la faisabilité d'implants permettant de localiser en temps réel des personnes ou encore de contrôler à distance les fonctions biologiques du corps humain. Des résultats sur la miniaturisation des puces RFID passives et implantables dans le corps sont présentés. Des considérations sur le choix de la fréquence de la communication sans fil entre l'implant RFID et son lecteur sont formulées. Deux techniques usuelles (à savoir le couplage inductif et le couplage électromagnétique) pour alimenter sans fil et à distance l'implant RFID passif et pour lire les données de l'implant sont décrites. Des applications biomédicales et thérapeutiques des implants RFID sont finalement données. 


\section{Introduction}

Implantable Radio Frequency Identification (RFID) devices are known as a technology for the remote identification (tagging) of animal or persons. A classical example of human identification based on RFID-implant is given by the VeriChip tag (11 mm long and about $1 \mathrm{~mm}$ in diameter) which contains numerical code (identifiers) readable at 10 centimeters or less using a handheld reader [Foster 2007]. When illuminating by the low-frequency magnetic field $(134 \mathrm{KHz})$ generated by the reader, the RFID tag powers itself up and transmits a 16-digit code that is unique to the tag. Recent developments in RFID technology have opened up new potential applications, where RFID devices are implanted in the human body for locating and tracking persons or for remotely controlling human biological functions. Such applications may raise ethical and juridical problems, but these are outside the scope of the present survey. In this paper only the advances and challenges in RFID technology for human implant devices are reported.

Sub-micron sized "spychip" implant connected to the Global Positioning System (GPS) is not achievable using the nowadays technology. A GPS device that would be required for the real-time tracking on earth presents dimensions that are too large for implanting inside human body. Miniaturization of such device for building a "rice-grain-sized GPS" implant is a very challenging technological issue that has to be solved before addressing the feasibility of "Human implant Personal GPS Tracker" [Masters 2005].

RFID technology for human implants is generally based on battery-less (passive) devices and allows achieving very short read range, typically $10 \mathrm{~cm}$ or much less (see, e.g., [Freudenthal 2007]). Consequently RFID implants cannot communicate with GPS satellites (or other equivalent satellite-based positioning system) that would be required for the real-time tracking of a person. RFID technology is then not suitable for the realtime tracking of a person anywhere on the planet through RFID-chip deeply implanted in his body.

The remote control of human biological functions by using RFID technology seems to be more realistic. Following the estimations of Burke et al. [Burke 2009], a single chip (including antenna) radio system with on-board sensors of size $100 \times 100 \times 1 \mu^{3}$ seems to be feasible with available technology. Consequently, the wireless communication with small RFID implants in humans for reading information about chemical or physical quantity in biological systems or for providing the remote activation/deactivation of biochemical activity inside a single living cell seems to be "not completely out of reach" [Burke 2009]. Moreover, using nanotechnology, Jensen et al. [Jensen 2007] have reported the fabrication of a FM-radio using a single nanotube of 
$1 \mu \mathrm{m}$ length and $10 \mathrm{~nm}$ width. The nanotube radio could be inserted inside the living human cell to give a subcellular remote and real-time controlled interface [Kumar 2008]. This recent result in miniaturization of radio-chip could also find application in fabrication of smartdusts [Cook 2006], i.e., tiny objects with sensing and communication abilities that may be massively distributed over some area for the remote tracking of human presence/displacement [Warneke 2001] (recent review presented in [Sailor 2005] discusses various techniques to take smartdust in sensor network beyond millimeter dimensions to the micrometer level). Another application could be on the fabrication of the very small physiological sensors implanted in human and communicating with a single central unit in Wireless Body Area Networks (WBAN) [Chen 2010].

Using current technology, a RFID device implanted inside the human body and wirelessly communicating with an off-body (or body-worn) reader can be very small and passive (see Section II): the smallest reported passive RFID device operating at $2.45 \mathrm{GHz}$ occupies an area of $400 \times 400 \mu \mathrm{m}^{2}$ [Usami 2004] (see Section III) while, at $13.56 \mathrm{MHz}$ a RFID device with an area of $2.5 \times 2.5 \mathrm{~mm}^{2}$ is available [Maxell 2010]. However the wireless communication with passive RFID device implanted inside the human body is generally performed at very short range. Based on inductive coupling (in free space) this range was measured to be $1 \mathrm{~cm}$ at $13.56 \mathrm{MHz}$ [Lu 2007] [Sasaki 2007] and shorter than $1 \mathrm{~mm}$ at $2.45 \mathrm{GHz}$ [Guo 2006] [Chen 2008] (see Section IV.1). Based on electromagnetic coupling (in free space) this range is between $1 \mathrm{~m}$ to $15.7 \mathrm{~m}$ at $900 \mathrm{MHz}$ and may reach $7.5 \mathrm{~cm}$ at $5.8 \mathrm{GHz}$ [Radiom 2010] (see section IV.2). For small passive transponders $(2 \mathrm{~mm} \times 10 \mathrm{~mm}$ ) deeply implanted in the human body (at $10 \mathrm{~cm}$ to $30 \mathrm{~cm}$ in depth) and power supplied by inductive coupling at $13.56 \mathrm{MHz}$, the read range was found to be shorter than $10 \mathrm{~cm}$ from the body [Freudenthal 2007].

This paper presents an overview on RFID technology for human implant devices. Section II reports the technical requirements that human implants having sensing and communication abilities have to satisfy. Justifications for the use of passive RFID devices implanted inside human body for achieving the remote electronic control at bio-molecular scale level conclude Section II. Section III is devoted to documented results on the miniaturization of RFID devices, while Sections IV.1 and IV.2 report wireless techniques for powering such devices. A discussion on the choice of the transmission frequency in wireless communication between RFID device implanted inside human body and an offbody interrogator is given in Section IV.3. Nowadays RFID devices implanted in the human body are expected (1) to transmit measurements of chemical or biological data inside the body and (2) to monitor biological activity or physiological functions of the human. Some published biomedical and therapeutic applications of human RFID-implant 
devices are finally reported in Section V. The conclusion identifies some technological challenges to face for demonstrating the feasibility of in-vivo remote control over human bio-molecular machinery.

\section{RFID technology for human implant devices}

\section{II.1 Technical requirements for human implant devices}

Many technical requirements have to be fulfilled by a human implantable device having sensing, computing and communication abilities. In-vivo implants have to be as small as possible. Moreover, it may be impractical to use a battery for supplying power to an electronic device injected into the body: the large size of batteries compromises their utilization and a passive (also called battery-less or fully autonomous) device may be preferred in practice. Another requirement concerns the selectivity of the remote control of human biological functions. For example, the remote control of a specific bio-molecular event inside a living cell has to be spatially localized for unaffecting other biological activities in the cell. Additionally bio-compatible material has to be used for fabricating the implant device and its packaging in order to avoid tissue reactions. Eventually, undesirable migration of the device inside the body has to be controlled or avoided. Moreover secure and reliable wireless transmission of the personal/confidential data recorded by the device inside the body has to be established. Guaranteed confidentiality and high reliability are certainly among the main criteria that must be given priority to implement such wireless technology. Finally, for safety issues related to antennas implanted in human tissue, electromagnetic energy radiated (or backscattered/reradiated) by an implant device for wirelessly communicating with the outside world must respect the IEEE human tissue exposure standard [IEEE 1999][IEEE 2002]. To satisfy safety recommendations, an implantable antenna operating at $868 \mathrm{MHz}$ when placed inside tissue layers has been designed in [Sani 2010] to ensure a Specific Absorption Rate (SAR) lower than $2 \mathrm{~W} / \mathrm{kg}$. In [Kim 2006] implantable antennas have been designed for operating at the Medical Implant Communications Service frequency band (402-405 $\mathrm{MHz}$ ), which is regulated by the Federal Communications Commission and the European Radiocommunications Committee for ultra-low-power active medical implants. To satisfy the recommendations of these institutions, antennas allowing a peak SAR lower than $1.6 \mathrm{~mW} / \mathrm{g}$ have been designed (estimation of the SAR in practical applications may be found in [Kim 2006]). 


\section{II.2 Remote control of molecular scale biochemistry}

The first attempt to demonstrate the feasibility of the remote electronic control at biomolecular scale level has been reported in 2002 by Hamad-Schifferli et al. [HamadSchifferli 2002]. The control of the hybridization behavior of DNA molecules has been performed by monitoring the heating of gold nanoparticles interfaced (linked) to DNA. Such local controlled heating performed by electromagnetic coupling at $1 \mathrm{GHz}$ induces the reversible hybridization/dehybridization of the DNA while leaving surrounding molecules relatively unaffected. Although the physics of heating nanometer particles has been little explored [Hanson 2009] and will certainly be the subject of future investigations, this experiment demonstrates for the first time the direct radio-frequency (RF) control over biomolecular machinery in a specific and fully reversible manner. Remote control at such very small scale level seems to not alter bio-molecular events occurring in the surrounding medium.

A discussion of the technological feasibility of tiny devices implanted inside a living cell for the remote control of a wide range of biological functions or the detection of presence or concentration of a protein or antibody can be found in [Burke 2009]. Based on known technological achievements and patents in nanoelectronics a "nanorobot" consisting in embedded smart sensors implanted in human body for tele-operated surgical procedures or early disease diagnosis has been designed in [Cavalcanti 2007]. Up to now, such nano-devices have not been fabricated.

\section{II.3 RFID Technology for human implant devices}

Basically, RFID is a technology that uses communication via electromagnetic waves to exchange data between an interrogator (also known as the reader) and an object called the transponder for identification and tracking purposes. The transponder is generally composed of an integrated circuit for storing and processing the data signal and an antenna for receiving and transmitting the signal [Finkenzeller 2003]. Such technology may fulfill the technical requirements listed Section II.1. Fabrication of very small RFID device with communicating ability is achievable (see Section III) and, following the recent estimations of Burke [Burke 2009], it appears technically possible to fabricate RFID device at the bio-molecular scale that interrogates its local chemical environment (sensing) or/and controls the biological machinery inside a single living cell. The remote monitoring at such a very small scale level is assumed to provide the selectivity requirement, that is, the local control of bio-molecular machinery without damaging cells or even affecting the biological events in the surrounding medium. 
Moreover RFID technology allows real-time remote monitoring of fully autonomous implants in human body (see Sections IV.1 and IV.2). In the power harvesting technique based on inductive or electromagnetic couplings, the RFID implant receives power from the interrogator and emits back to it a signal that contains data. For such passive solution RF power deposition inside tissue can be easily made compliant with safety regulations mentioned in Section II.1. In addition some technical requirements, relative to the fabrication of bio-compatible implant devices and to the establishment of secure and reliable wireless transmission of data recorded by implants, have already been addressed in the framework of RFID technology and preliminary solutions have been found (see e.g., [Ricardi 2003] and [Sauer 2005]). The read range of communication for RFID implanted in human body is found to be shorter than $10 \mathrm{~cm}$ (see Section IV). Such short read range could be advantageous when RFID implants are subject to security/confidentiality requirement.

\section{Technological results on the miniaturization of RFID devices}

From the review of the state of the art it can be observed that size of single chip RFID transponders with available technology is dominated by the antenna size and not by one of the integrated circuit (IC) used by the RFID transponder for storing and processing the data signal. The smallest size of the IC is $50 \times 50 \times 5 \mu \mathrm{m}^{3}$ without antenna, i.e., for an offchip antenna [Usami 2003][Hitachi 2007][Usami 2007]. However, using either electromagnetic waves or inductive coupling for powering passive RFID device (see Sections IV.1 and IV.2) an off-chip antenna is typically $\mathrm{cm}$ in size. Smaller RF antennas (typically few $\mathrm{mm}$ by a few $\mathrm{mm}$ in size) can be fabricated when incorporating antenna on the same chip as the signal processing components (on-chip antenna or OCA). Using $0.25 \mu \mathrm{m}$ CMOS technology Abrial et al. [Abrial 2001] have reported in 2001 a System-OnChip (operating at $13,56 \mathrm{MHz})$ including coil antenna $\left(1.5 \mathrm{~mm}^{2}\right)$, RF communication and digital processing within a surface of $16 \mathrm{~mm}^{2}$ (including pads) while Maxell Corp. [Maxell 2010] has reported an OCA designed on a chip area of $2.5 \mathrm{~mm} \times 2.5 \mathrm{~mm}$. At the same operating frequency, a mini-RFID transponder occupying an area of $8 \times 3 \mathrm{~mm}^{2}$ (and a volume of $25 \mathrm{~mm}^{3}$ ) has been recently published in [Lu 2007]. At 2.45GHz, a RFID chiparea of $1 \times 0,5 \mathrm{~mm}^{2}$ has been reported [Guo 2006], while using $0.18 \mu \mathrm{m}$ CMOS technology, Usami et al. have presented in 2004 a smaller RFID chip occupying an area of $400 \times 400 \mu \mathrm{m}^{2}$ only [Usami 2004] [Usami 2004b][Usami 2006]. Using existing CMOS technology, Burke et al. estimate that the fabrication of a RFID-chip volume of $100 \times$ $100 \times 5 \mu \mathrm{m}^{3}$ "is not completely out of reach" [Burke 2009]. 
New manufacturing techniques at nano-scale level may help to miniaturize RFID devices. It may allow, for example, exploring the feasibility of very small antenna by using a carbon nanotube (overview of the high-frequency properties nanotube and nanowire technology for microwave applications can be found in [Burke 2005]). Using a single carbon nanotube Jensen et al. have reported in 2007 the first nano-sized radio-wave receivers [Jensen 2007]. A single carbon nanotube in vacuum ( $0.1 \mu$ Torr) of $1 \mu \mathrm{m}$ length and $10 \mathrm{~nm}$ diameter served at the same time as antenna, tuner, amplifier and frequency demodulator. The antenna receives signals via high-frequency mechanical vibrations of the nanotube and the magnitude of these vibrations is high only when the frequency of the incident wave coincides with the (tunable) resonance frequency of the nanotube. $A$ battery has been connected as a power source for the operation of the radio and consequently, a transmission and reception of signals on a distance of several meters may be achieved with this active devices. Another tiny radio using nanotechnology is also demonstrated in [Rutherglen 2007] where a carbon nanotube is used to demodulate amplitude modulated signal. These advances in fabrication of radio-chip at nano-scale level may help the advent of nano-scale RFID device. Due to the small size, such devices may then potentially be inserted inside the living human cell to provide a sub-cellular remote controlled interface.

\section{Wireless techniques for powering passive RFID implant devices}

Passive RFID technology allows to overcome the limitations in terms of lifetime, reliability and size of RFID devices requiring a battery. The electromagnetic field received from the interrogator is the only source for supplying power to the passive transponder. The two techniques currently used for wirelessly supplying power to (and read data from) passive RFID chip are reported in this Section. The analysis given in Sections IV.1 and IV.2 are performed in free-space environment and in absence of electromagnetic noise, while Section IV. 3 considers the performances of actual wireless communication between an implanted RFID device and an off-body interrogator.

\section{IV.1. Inductive coupling}

The power required for operating a passive transponder may be supplied by an interrogator via inductive (or near field) coupling. Figure 1(a) shows the constitutive elements of the corresponding RFID system. Time-harmonic magnetic field is generated by the low frequency current in the interrogator coil. In the near field region inductive coupling may occur between this coil and the transponder coil. 

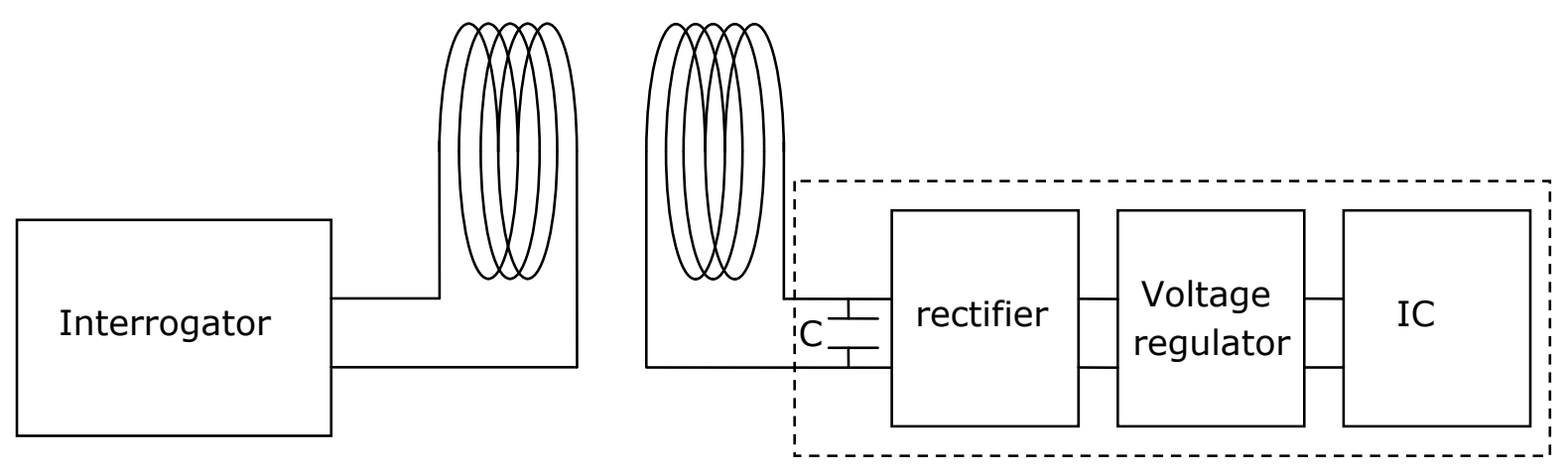

Transponder

(a)

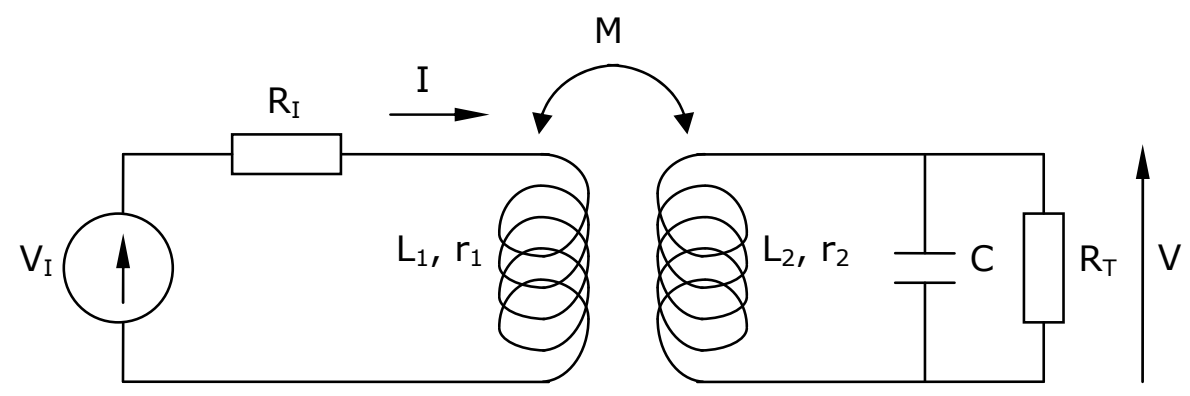

(b)

Figure 1 : RFID system based on inductive coupling: (a) Constitutive elements and (b) equivalent circuit

The equivalent circuit of the RFID system based on inductive coupling is shown in Figure 1(b). The resistor $R_{T}$ models the total losses in the integrated circuit (IC) used by the RFID transponder for storing and processing the data signal. $L_{1}$ and $L_{2}$ represent the transponder and the interrogator coil inductances, respectively, while $M$ denotes the mutual inductance. $r_{1}$ and $r_{2}$ are the series resistances of the interrogator and transponder coils, respectively. The capacitor $C$ connected in parallel with the transponder antenna coil $L_{2}$ form a resonant circuit at the chosen transmission frequency f. Then the magnitude $V$ of the time-harmonic voltage at the terminal of $L_{2}$ given by (see, e.g. [Finkelzeller 2003]):

$$
\mathrm{V}=\frac{\omega \mathrm{k} \sqrt{\mathrm{L}_{1} \mathrm{~L}_{2}}}{\sqrt{\left(\frac{\mathrm{L}_{2} \omega}{\mathrm{R}_{\mathrm{T}}}+\mathrm{r}_{2} \mathrm{C} \omega\right)^{2}+\left(1-\mathrm{L}_{2} \mathrm{C} \omega^{2}+\frac{\mathrm{r}_{2}}{\mathrm{R}_{\mathrm{T}}}\right)^{2}}} \mathrm{I}
$$


It reaches its maximum value at resonance frequency. In Eq. (1), I denotes the magnitude of the time-harmonic current in the interrogator coil, $\omega=2 \pi f$ is the radian frequency of the transmission. The coupling coefficient $\mathrm{k}=\mathrm{M} / \sqrt{\mathrm{L}_{1} \mathrm{~L}_{2}}$ between the two coils depends on the distance $d$ between the transponder coil and the interrogator coil. In practice this coefficient is close to $10^{-3}$ (e.g., $\mathrm{k}=410^{-3}$ at a distance $\mathrm{d}=5 \mathrm{~mm}$ and $\mathrm{k}=$ $1.510^{-3}$ at $d=1 \mathrm{~cm}$ in [Lu 2007]). The voltage $\mathrm{V}$ given by Eq (1), once rectified and smoothed with a regulator, is used for supplying power to the IC. It must be large enough to operate this circuit. For a given distance $d$ between the two coils, this condition allows to derive the minimum magnetic field that must be generated by the interrogator coil.. This field decreases rapidly with distance inside the near field region (as $1 / d^{3}$ where $d$ designates the distance from the center of the interrogator coil to the transponder coil [Finkelzeller 2003]) and consequently, when the two coils are separated, it may rapidly become too weak for providing the transponder with the energy it needs to operate. From [Lu 2007], at a frequency $f=13.56 \mathrm{MHz}$, voltages $\mathrm{V} \approx 1$ Volt (required for operating the RFID IC) may be induced in a small implantable transponder coil $\mathrm{L}_{2} \approx$ $100 \mathrm{nH}$ from an interrogator coil $\mathrm{L}_{1} \approx 1 \mu \mathrm{H}$ located at a distance $\mathrm{d}$ smaller than $1 \mathrm{~cm}$.

Lu et al. [Lu 2007] have recently reported wireless communication with implantable RFID device (occupying approximately $25 \mathrm{~mm}^{3}$ in volume) in the frequency range of 13.56-27 $\mathrm{MHz}$ at a distance of $1 \mathrm{~cm}$. A successful wireless communication at $13.56 \mathrm{MHz}$ has also been established by Sasaki et al. [Sasaki 2007] at the same distance. Guo et al. [Guo 2006] have reported a successful communication with a small $2.45 \mathrm{GHz}$ RFID device (with a chip-area of $1 \mathrm{~mm} \times 0,5 \mathrm{~mm}$ ) at a distance of $1 \mathrm{~mm}$. The design of a 2.45-GHz RFID device with its on-chip antenna smaller than $0.5 \mathrm{~mm}^{2}$ with a thickness of $0.1 \mathrm{~mm}$ is reported in [Chen 2008]: with the reader generating an output power of $500 \mathrm{~mW}$, the RFID system was able to perform with RF read/write functions at a distance smaller than $0.5 \mathrm{~mm}$.

\section{IV.2. Electromagnetic coupling}

The technique based on electromagnetic (or far field) coupling involves the use of electromagnetic waves that propagate from the antenna in the far field region to power the passive RFID chip. To transmit data, the IC changes the impedance of the transponder antenna which backscatters some of the incident RF energy to the interrogator. Figure 2(a) shows the constitutive elements of the RFID system based on such a coupling. 

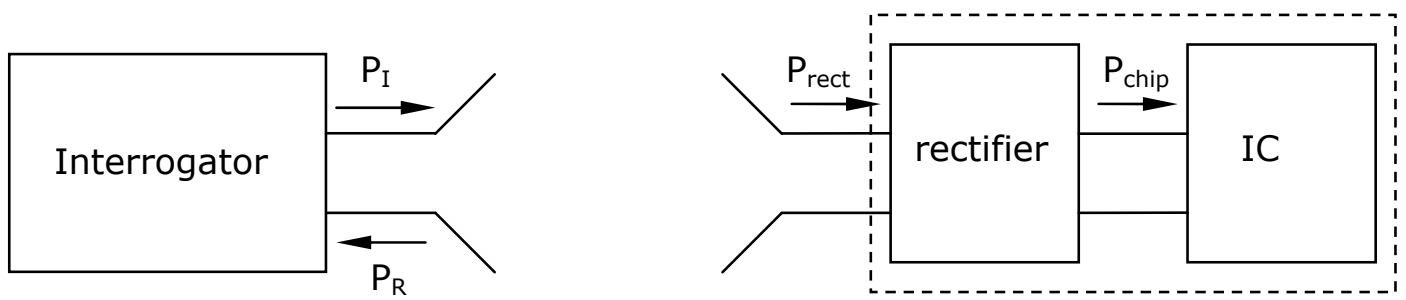

Transponder

Figure 2 : Constitutive elements of a RFID system based on electromagnetic coupling

In free-space, the electromagnetic power $\mathrm{P}_{\text {rect }}$ received by the transponder antenna (gain $\mathrm{G}_{\mathrm{T}}$ ) is given by [Balanis 2005]:

$$
P_{\text {rect }}=G_{I}\left(\frac{\lambda}{4 \pi d}\right)^{2} G_{T} P_{I}
$$

where $P_{I}$ designates the power transmitted by the interrogator antenna (gain $G_{I}$ ), $\lambda$ is the free-space wavelength and $d$ denotes the distance between the interrogator and transponder antennas (polarization mismatch between antennas is assumed negligible. This can be obtained by choosing appropriate antenna orientation). The attenuation factor $\left(\frac{\lambda}{4 \pi \mathrm{d}}\right)^{2}$ is called the free-space path loss. The power $P_{R}$ back-scatters by the transponder is given by [Balanis 2005]:

$$
P_{R}=\sigma \frac{\left(\lambda_{0} G_{I}\right)^{2}}{(4 \pi)^{3} d^{4}} P_{I}
$$

where $\sigma$ designates the radar cross-section of the transponder, that is, the efficiency with which the transponder reflects incoming electromagnetic waves. As it can be observed from Eq.(3), power is strongly attenuated by a factor $1 / d^{4}$ (in free-space) when it returns back to the interrogator. The range of the wireless reading of the transponder data can be derived from the interrogator sensitivity $P_{R \min }$

Systems based on electromagnetic coupling operate usually at UHF frequencies of $868 \mathrm{MHz}$ (Europe) and $915 \mathrm{MHz}$ (USA) and at microwave frequencies of $2.5 \mathrm{GHz}$ and $5.8 \mathrm{GHz}$ [Finkelzeller 2003]. Jia et al. [Jia 2008] have reported a RFID humidity sensor capable of passive wireless sensing at $868 \mathrm{MHz}$. The reader antenna was positioned at a fixed distance of $1.5 \mathrm{~m}$ in front of the RFID chip. Very recently, a great improvement with respect to performances of existing passive UHF/microwave RFID chip has been reported 
in [Radiom 2010]: a fully integrated and implantable 900MHz RFID chips has been fabricated and the measured range is found to be $15.7 \mathrm{~m}$, assuming an off-chip $\mathrm{G}_{\mathrm{T}}=0 \mathrm{~dB}$ antenna gain, while the device with its on-chip antenna operating at $5.8 \mathrm{GHz}$ can be read and powered-up up to $7.5 \mathrm{~cm}$ distance.

A passive RFID device incorporating sensor based on electromagnetic transduction has been recently proposed in [Jatlaoui 2007][Jatlaoui 2008][Jatlaoui 2009]. By using this device wireless data transmission and measurement of the physical quantity (e.g., pressure, temperature, gas concentration) can share the same electromagnetic wave. No electronics, no rectifier and no IC are needed and consequently, the overall RFID device losses are minimized. This allows transmission ranges of some tens of meters. Based on this technique, passive RFID devices incorporating pressure sensor [Jatlaoui 2008b][Jatlaoui 2009b][Jatlaoui 2009c][Jatlaoui 2009d][Jatlaoui 2010][Jatlaoui 2010b], temperature sensor [Thai 2010][Thai 2010b] or gas concentration sensor [Hamida 2010][Hamida 2010b][Hamida 2009][Hamida 2009b][Hamida 2009c] have been successfully tested.

\section{IV.3 Frequency and read range in wireless communication between RFID device implanted inside human body and an off-body interrogator}

Low frequency (LF) electromagnetic waves are not strongly attenuated by human tissues. However the read range associated with LF (135 KHz) RFID implant is generally shorter than $1 \mathrm{~m}$ due to rapid attenuation of the magnetic field with distance (see Section IV.1) and the necessarily small cross-sectional area of implanted transponder coil antenna. Moreover the bandwidth of LF RFID chip is very small. This technical characteristic implies: (1) very slow data rates (low data transfer), (2) inability of the interrogator to read simultaneously multiple RFID implant devices, (3) vulnerability to transmission collapse in presence of strong environmental electrical noise (lack of robustness and reliability of the wireless link) and (4) difficulty to incorporate any cryptography in the transmitted signal (lack of security/confidentiality of the data transfer, although the very short range associated with such close coupling systems could be interesting for achieving secure transmission).

In [Freudenthal 2007] the authors investigate the effectiveness of High Frequency (HF) waves for communicating with implanted devices. Considerations that may justify the use of HF RFID for implanted medical applications can also be found in [Magellan 2006]. HF waves ranging from $1 \mathrm{MHz}$ to $20 \mathrm{MHz}$ are not significantly attenuated by human tissues 
and thus are suitable for communication with RFID devices implanted inside the human body [Villancourt 1997]. Experiments performed at $4 \mathrm{MHz}$ emulating the human tissue electrical properties by introducing water bearing colloids between coils of the inductive coupling RFID system have revealed a small decrease in the amount of power transmitted by the interrogator to the transponder [Sauer 2005]. This attenuation was not large enough to cause data or power flow disruption or to lower the power supply voltage below the IC operating range. The read range of such HF inductive coupling system was then found to be quite the same than one observed in free space environment (that is $1 \mathrm{~cm}$ at $13.56 \mathrm{MHz}$ and shorter than $1 \mathrm{~mm}$ at $2.45 \mathrm{GHz}$ ). Moreover successful wireless communication with ten HF RFID devices (each one occupying an area of $2 \times 10 \mathrm{~mm}^{2}$ ) implanted at three locations within a human body (at $10 \mathrm{~cm}$ to $30 \mathrm{~cm}$ in depth) has been established in [Freudenthal 2007]. It has been observed that deeply implanted transponders may be read at distance of $10 \mathrm{~cm}$ from the body, i.e., at distances-to-transponders similar to those observed for non implanted transponders.

From the review of state of the art it can be observed that inductive coupling operating in $\mathrm{HF}$ (13.56 $\mathrm{MHz}$ and below) frequency range is now one of the most common methods to wirelessly send power and data from off-body interrogator to RFID device implanted inside human body. In 1988, the design of millimeter- and sub-millimeter-sized power sources operating at $2 \mathrm{MHz}$ and $20 \mathrm{MHz}$ for neural implant based on inductive coupling has been proven feasible [Heetderks 1988]. Power harvesting of implanted devices through inductive coupling has been successfully performed for various applications, e.g, for recording the neural signals from axons by using implanted telemetry system occupying an area of $4 \times 6 \mathrm{~mm}^{2}$ and operating at $2 \mathrm{MHz}$ [Atkin 1998], for wireless implantable neural micro-stimulation system [Ghovanloo 2004b], or for replacing defective photoreceptors in patients by implanting a retinal chip that achieves the transmission link between the extra-ocular and intraocular coil antennas at a frequency ranging from 1 to $10 \mathrm{MHz}$ [Liu 2000].

Ultra-High Frequency (UHF) RFID device offers significantly higher bandwidth than LF or HF RFID. This allows, e.g., high data rates and the incorporation of privacy/integrity preserving cryptographic protocols for wireless transmission in order to protect information [Juels 2006]. Moreover, using UHF electromagnetic waves, high level of miniaturization of RFID chip (including its antenna) can be achieved (see Section III). However UHF waves may be problematic for human RFID implants, due to the following reasons: (1) UHF and microwave fields are strongly attenuated by water (which is the primary constituent of human tissue) and consequently a passive RFID solution allows a very limited communication range (typically shorter than $1 \mathrm{~m}$ ); (2) the UHF field 
transmitted by an interrogator located outside the human body is subject to multiple reflections by environmental objects creating interferences and undesirable shadow zones (in which RFID chip is not detectable by the interrogator) and peaks or hot spot in the field distribution; (3) HF frequencies (in particular $2.45 \mathrm{GHz}$ ) may be unsafe for human for long-term exposure and/or when high electromagnetic densities are involved.

In the UHF band the human body, essentially composed of water, bones and tissues, can be viewed as a highly scattering and dissipative electromagnetic propagation channel in which multiple reflections (multi-paths) and strong attenuation occur. Specifically input impedance and radiation pattern of the transponder antenna may depend on the location of the antenna implanted inside the body [Kim 2006]. In order to perform an analysis of the UHF wireless communication efficiency and to analysis electromagnetic characteristics of antennas implanted inside the human body, a realistic electromagnetic model of the human body (with its various tissues and geometries) has to be elaborated. It will allow designing a reliable wireless communication system between a RFID device implanted inside human body and an off-body interrogator. The propagation analysis of UHF electromagnetic field in muscle tissue has been presented in [Arumugam 2008] while in [Kim 2006] [Sani 2010] the authors analyze the antenna performances (efficiency, radiation pattern, and input impedance) when implanted in human body or in an equivalent simplified tissue model. In [Kim 2006] it is observed that the return-loss characteristics of $400 \mathrm{MHz}$ antennas change with the location of the antennas inside the tissue-simulating fluid. The resulting range of the wireless communication with an UHF RFID-implant may then be greatly dependent on the implant location in human body.

At an operating frequency between $915 \mathrm{MHz}$ and $1 \mathrm{GHz}$ wireless communication between a transponder antenna and an interrogator antenna separated by $15 \mathrm{~mm}$ of bovine muscle tissue has been established by [O'Driscol 2009]. In [Warty 2008] communication between antennas positioned below the scalp covering the frontal region of the skull was presented and the effect of the antenna packaging on the impedance matching of an implanted antenna was also analyzed. Using an inductively powered and implantable wireless neural recording device working at $3.2 \mathrm{GHz}$, the in-vivo continuous recording continuous of Electro-Encephalogram from the hippocampus of an un-tethered rat is possible [Irazoqui-Pastor 2003]. 


\section{Biomedical/therapeutic applications of human RFID-implant devices}

For biomedical applications RFID-implant devices are expected to transmit various chemical or biological parameters measured inside the body. Such devices can be used by diabetes sufferers [M-Biotech]: a wireless alarm unit implanted in the abdominal region of the patient, continually reads the data of a sensor chip sensitive to glucose concentration of surrounding fluids. Recently, Sauer et al. [Sauer 2005] have used RFIDimplant technology for in vivo data collecting and wirelessly transmission of electroencephalograms taken during animal recording.

For therapeutic applications RFID-implant devices are expected to monitor biological activity or physiological functions of human body and to modify them. Example is provided by the monitoring of brain function via implanted probes implanted that communicate via a transponder embedded within the skull [McCreery 2006b][McCreery 2006]. An array of 16 activated iridium microelectrodes (5-6 $\mathrm{mm}$ in length within a cluster approximately $1.8 \mathrm{~mm}$ in diameter) suitable for long-term implantation into the brain, records signal from single neurons, and delivers as well localized microstimulation. These microelectrodes may also be used therapeutically [Freudenthal 2007]. However such therapeutic applications of RFID implants are still at the proof of concept stage. The benefits of such technology in terms of, e.g., improvement of quality of living or of patient care, have to be demonstrated.

\section{Conclusion}

RFID technology has opened up new expectations in the fabrication of tiny devices implanted in the human body for locating and tracking persons or for remotely controlling human biological functions. A RFID-chip implanted inside the human body can transmit its data to an off-body interrogator at very short distance (typically $10 \mathrm{~cm}$ or less). It cannot communicate, e.g., with GPS satellites (or other equivalent satellite-based positioning system) that would be required for the real-time tracking of a person. RFIDtechnology is then not suitable for the real-time tracking of a person anywhere on the planet through RFID-chip deeply implanted in its body. However, a RFID-based remote and reversible control of human bio-molecular machinery seems to be not completely out of reach using existing technology [Burke 2009]. The recent advances in fabrication of radio-chip at nano-scale level [Jensen 2007] [C. Rutherglen, 2007] may help the advent of nano-scale RFID chip. Due to their small size, such device could be inserted inside the human living cell to provide a sub-cellular remote controlled interface. 
Many technological problems have to be solved for demonstrating the feasibility of the reliable remote control of human bio-molecular machinery using RFID implants: heat removal and elaboration of bio-compatible miniaturized packaging are two of them [O 2005]. Other questions have to be addressed: Could new power harvesting technique based on the properties of surrounding human tissue be exploited for supplying power to RFID devices implanted inside the body? Would electromagnetic fields transmitted by nano-radio implant damage surrounding tissue? Despite very promising recent technological advances, many challenges must be addressed for clearly validating the expected benefits of RFID-implant technology.

\section{References}

[Abrial 2001] A.Abrial, J.Bouvier, M. Renaudin, P. Senn, P. Vivet, "A new Contactless Smart Card IC using an on-chip antenna and an asynchronous microcontroller," IEEE J. Solid-State Circuits 36(7), 1101-1107 (2001)

[Arumugam 2008]

D.D. Arumugam, D. W. Engels, "Characterization of RF Propagation in Muscle Tissue for Passive UHF RFID Tags," XXIX General Assembly of the International Union of Radio Science URSI, Chicago, August $7^{\text {th }}$ to $17^{\text {th }} 2008$.

[Atkin 1998] T. Akin, K. Najafi, and R. M. Bradley, "A wireless implantable multichannel digital neural recording system for a micromachined sieve electrode," IEEE J. Solid-State Circuits, vol. 33, no. 1, pp. 109-118, Jan.1998.

[Balanis 2005] C.A. Balanis : Antenna Theory - Analysis and design, Third Edition, John Wiley \& Sons, 2005.

[Burke 2005] P.J. Burke, Z. Yu, S. Li, and C. Rutherglen,"Nanotube Technology for Microwave Applications," Proc. of IEEE MTT International Microwave Symposium 2005 (2005).

[Burke 2006] P. J. Burke, S.Li, Z. Yu," Quantitative theory of nanowire and nanotube antenna performance," IEEE Trans. Nanotechnol. 5(4), 314-334 (2006)

[Burke 2009] Peter Burke, Christopher Rutherglen, «Towards a single-chip, implantable RFID system: is a single-cell radio possible?", Biomed Microdevices, 24 January 2009

[Cavalcanti 2007]Ariano Cavalcanti, Bijan Shirinzadeh, Robert A. Freitas Jr. and Luiz C. Kretly, "Medical Nanorobot Architecture Based on Nanobioelectronics" Bentham Science Publishers Ltd., Recent Patents on Nanotechnology 2007. Vol. 1. No. 1. (Feb. 2007) available at : http://www.bentham.org/nanotec/samples/nanotec1-1/Cavalcanti.pdf

[Chen 2008] X. Chen, W.G.Yeoh, Y. B.Choi, H. Li, R. Singh, “A 2.45-GHz Near-Field RFID System With Passive On-Chip Antenna Tags," IEEE Trans. Microw. Theory Tech., Vol.56, No. 6, June 2008

[Chen 2010] Chen, M., Body Area Networks: A Survey, ACM/Springer Mobile Networks and Applications (MONET), 2010.

[Cook 2006] W. Cook, S.Lanzisera, K. S. J. Pister "SoC Issues for RF Smart Dust," Proceedings of the IEEE, vol. 94, No. 6, June 2006,

[Finkenzeller 2003]

K. Finkenzeller, RFID handbook: fundamentals and applications in contactless smart cards and identification, Wiley, Hoboken, N.J., 2003

[Foster 2007] K.R. Foster, J. Jaeger, "IEEE Spectrum: RFID inside," http://spectrum.ieee.org/print/4939, July 2007

[Freudenthal 2007]

E. Freudenthal, D. Herrera, F. Kautz, C. Natividad, A. Ogrey, J. Sipla, A. Sosa, C. Betancourt, L. Estevez, Leonardo, "Evaluation Of HF RFID for Implanted Medical Applications" (2007). Departmental Technical Reports (CS). Paper 162., http://digitalcommons.utep.edu/cs_techrep/162 
Comptes rendus à l'Académie des Sciences Special issue on nanosciences/nanotechnologies

March 1st, 2011

Hervé AUBERT

[Ghovanloo 2004b]

M. Ghovanloo and K. Najafi, "A wide-band frequency-shift keying wireless link for inductively powered biomedical implants," IEEE Trans. Circuits Syst. I, Reg. Papers, vol. 51, no. 12, pp. 2374-2383, Dec. 2004.

[Guo 2006] L.H. Guo, A.P. Popov, H. Y. Li, Y. H. Wang, V. Bliznetsov, G. Q. Lo, N. Balasubramanian, D.-L. Kwong, "A small OCA on a $1 \times 0.5-\mathrm{mm} 2$ 2.45-GHz RFID tag-design and integration based on a CMOS-compatible manufacturing technology," IEEE Electron Device Lett. 27(2), 96- 98 (2006)

[Hamad-Schifferli 2002]

K. Hamad-Schifferli, J.J. Schwartz et al., Remote electronic control of DNA hybridization through inductive coupling to an attached metal nanocrystal antenna Nature 415(6868), 152155 (2002)

[Hamida 2010] H. Hallil, F. Chebila, P. Menini, H. Aubert, "Feasibility of Passive Gas Sensor Based on Whispering Gallery Modes and its RADAR Interrogation: Theoretical and Experimental Investigations," Sensors \& Transducers journal, Vol.116, Issue 5, May 2010, pp.38-48

[Hamida 2009] H. Hallil, P. Menini, H. Aubert, "Novel Microwave Gas Sensor Using Dielectric Resonator with SnO2 Sensitive Layer", Eurosensors 2009, Lausanne, Switzerland, 6-9 September, 2009.

[Hamida 2009b] H. . Hallil, P. Menini, H. Aubert, "New microwave gas detector using dielectric resonator based on a Whispering-Gallery-Mode," European Microwave Week, Nuova Fiera di Roma, Rome, Italy, 28 september - 2 October 2009.

[Hamida 2009c] H. Hallil, P. Menini, H. Aubert,, "Novel Millimeter-Wave Gas Sensor Using Dielectric Resonator with sensitive layer on TiO2", 8th IEEE Conference on Sensors, Christchurch, New Zealand, 25-28 October, 2009.

[Hamida 2010b] H. Hallil, F. Chebila, P. Menini, P. Pons, H. Aubert, "Feasibility of Wireless Gas Detection with an FMCW RADAR Interrogation of Passive RF Gas Sensor," The $9^{\text {th }}$ Annual IEEE Conference on Sensors (IEEE Sensors 2010), November 1-4, 2010, Waikaloa, Hawaï, USA.

[Hanson 2009] G.W. Hanson, S. K. Patch2, "Optimum electromagnetic heating of nanoparticle thermal contrast agents at RF frequencies," Journal of Applied Physics 106, 054309, 2009.

[Heetderks 1988]

W. J. Heetderks, "RF powering of millimeter- and submillimeter-sized neural prosthetic implants," IEEE Trans. Biomed. Eng., vol. 33, no. 3, pp. 323-327, Mar. 1988.

[Hitachi 2007] http://www.engadget.com/2007/02/14/hitachis-rfid-powder-freaks-us-the-heck-out

[IEEE 1999] IEEE standard for safety levels with respect to human exposure to radio frequency electromagnetic fields, $3 \mathrm{kHz}$ to $300 \mathrm{GHz}$, IEEE Standard C95.1-1999, 1999.

[IEEE 2002] IEEE recommended practice for measurements and computations of radio frequency electromagnetic fields with respect to human exposure to such fields, $100 \mathrm{kHz}$ to $300 \mathrm{GHz}$, IEEE Standard C95.3- 2002, 2002.

[Irazoqui-Pastor 2003]

P. Irazoqui-Pastor, I. Mody, and J. W. Judy, "In-vivo EEG recording using a wireless implantable neural transceiver," in Proc. 1st Int. IEEE EMBS Conf. Neural Engineering, vol. 1, 2003, pp. 622-625.

[Jatlaoui 2007] M.M.Jatlaoui, P.Pons, H.Aubert, "Radio- Frequency pressure transducer," 37th European Microwave Conference (EuMC'07), München, Germany, 8-12 October 2007, pp.983-986

[Jatlaoui 2008] M.M.Jatlaoui, P.Pons, H.Aubert, "Pressure Micro-sensor based on Radio-Frequency Transducer," IEEE International Microwave Symposium (IMS), Atlanta, Georgia, USA, 15- 20 June 2008

[Jatlaoui 2009] M.M.Jatlaoui, F.Chebila, I.Gmati, P.Pons, H.Aubert, "New Electromagnetic Transduction Microsensor Concept For Passive Wireless Pressure Monitoring Application," Transducers 2009, 15th International Conference on Solid-State Sensors, Actuators and Microsystems, June 21-25, 2009, Denver, Colorado, USA.

[Jatlaoui 2008b] M.M.Jatlaoui, F.Chebila, P.Pons, H.Aubert, "Pressure Sensing Approach Based on Electromagnetic Transduction Principle," 2008 Asia Pacific Microwave Conference (APMC 2008), Hong Kong and Macao, China, 16-19 December 2008

[Jatlaoui 2009b] M. M. Jatlaoui, F. Chebila, P. Pons, H. Aubert, "Wireless Interrogation Techniques for a Passive Pressure Micro-sensor using an EM Transducer," European Microwave Week, Nuova Fiera di Roma, Rome, Italy, 28 september - 2 October 2009 
Comptes rendus à l'Académie des Sciences Special issue on nanosciences/nanotechnologies

March 1st, 2011

Hervé AUBERT

[Jatlaoui 2009c] M. M. Jatlaoui, F. Chebila, P. Pons, H. Aubert, "Wireless Interrogation Techniques for a Passive Pressure Micro-sensor using an EM Transducer," European Microwave Week, Nuova Fiera di Roma, Rome, Italy, 28 september - 2 October 2009.

[Jatlaoui 2009d] M.M.Jatlaoui, F.Chebila, P.Pons, H. Aubert, "New Micro-sensors Identification Techniques Based on Reconfigurable Multi-band Scatterers," 2009 Asia-Pacific Microwave Conference (APMC 2009), Singapore, December 7-10, 2009.

[Jatlaoui 2010] M. M. Jatlaoui, F. Chebila, S. Bouaziz, P. Pons, H. Aubert, "Original Identification technique of passive EM Sensors using Loaded Transmission Delay Lines," European Microwave Week (EuMW 2010), 26 September - 1 October 2010, Paris, France.

[Jatlaoui 2010b] M. M. Jatlaoui, F. Chebila, T. Idda, P. Pons, H. Aubert, "Phenomenological theory and experimental characterizations of passive wireless EM pressure micro-sensor prototype," The $9^{\text {th }}$ Annual IEEE Conference on Sensors (IEEE Sensors 2010), November 1-4, 2010, Waikaloa, Hawaï, USA.

[Jensen 2007] K. Jensen, J. Weldon, H. Garcia, and A. Zettl, "Nanotube radio,' Nano Lett. 7(11), 3508- 3511 (2007)

[Jia 2008] Y. Jia, M. Heiss, Q. Fu, N.A. Gay, "A prototype RFID humidity sensor for built environment monitoring", 2008 International Workshop on Education Technology and Training \& 2008 International Workshop on Geoscience and Remote Sensing, pp. 496-9, 2008

[Juels 2006]. A. Juels. RFID Security and Privacy: A Research Survey. Journal of Selected Areas in Communication (J-SAC), 24(2):381-395, February 2006.

[Kim 2006] J. Kim and Y. Rahmat-Samii, "Planar inverted-F antennas on implantable medical devices: Meandered type versus spiral type," Microw. Opt. Technol. Lett., vol. 48, no. 3, pp. 567-572, 2006.

[Kumar 2008] Ujjal Kumar Sur, “World's first single carbon nanotube radio," Current Science, Vol. 94, No. 2, January 2008

[Liu 2000] W. Liu, K. Vichienchom, M. Clements, S. C. DeMarco, C. Hughes, E. McGucken, M. S. Humayun, E. De Juan, J. D. Weiland, and R. Greenberg, "A neuro-stimulus chip with telemetry unit for retinal prostheticdevice," IEEE J. Solid-State Circuits, vol. 35, no. 7, pp. 1487-1497, Jul. 2000.

[Lu 2007] Lu, H.M.; Goldsmith, C.; Cauller, L.; Jeong-Bong Lee.: "MEMS-Based Inductively Coupled RFID Transponder for Implantable Wireless Sensor Applications," IEEE Transactions on Magnetics, Volume 43, Issue 6. (June 2007) 2412 - 2414.

[McCreery 2006b]

D. McCreery, A. Lossinsky, V. Pikov, and X. Liu, "Microelectrode array for chronic deep-brain microstimulation and recording," IEEE Trans Biomedical Engineering, vol. 53, no. 4, April 2006.

[McCreery 2006]

D. McCreery, "Microelectrode array for chronic deep-brain microstimulation for recording," US 3006/0276866 A1, December 2006

[Magellan 2006]

Magellan Technology. (2006, March) White paper: A comparison of RFID frequencies and protocols. [Online]. Available: http://www.magtech.com.au/downloads/White Paper Frequency Comparison 31 March 2006-1-1.pdf

[Master 2005] A. Masters, K. Michael, "Humancentric Applications of RFID Implants: The Usability Contexts of Control, Convenience and Care," Proceedings of the 2005 Second IEEE International Workshop on Mobile Commerce and Services (WMCS'05), 2005

[Maxell 2010] "Coil-on-chip RFID tag," Maxell, Fairlawn, NJ, 2010. [Online]. Available: http://www.maxellusa.com/index.aspx?id=4;41;432;0

[M-Biotech] M-Biotech, "Biosensor Technology", M-Biotech, Salt Lake City, 2003, http://www.mbiotech.com/technology1.html

[O 2005] K.K. O, K. Kim, B. A. Floyd, J. L. Mehta, H. Yoon, C.-M. Hung, D.Bravo, T. O. Dickson, X. Guo, R. Li, N. Trichy, J. Caserta, W. R. Bomstad, II, J.Branch, D.-J. Yang, J. Bohorquez, E. Seok, L. Gao, A. Sugavanam, J.-J. Lin, J. Chen, J. E. Brewer, "On-Chip Antennas in Silicon ICs and Their Application,"III Trans. Electron Devices, Vol. 52, No. 7, July 2005.

[Radiom 2010]

S.Radiom, M. Baghaei-Nejad, G. Vandenbosch, L.-R. Zheng, G. Gielen, "Far-field RF Powering System for RFID and Implantable Devices with Monolithically Integrated On-Chip Antenna," 2010 IEEE Radio Frequency Integrated Circuits Symposium, 2010 
Comptes rendus à l'Académie des Sciences Special issue on nanosciences/nanotechnologies

March 1st, 2011

Hervé AUBERT

[Reinhold 2007]

C. Reinhold, P.Scholz, W.John,U.Hilleringmann "Efficient Antenna Design of Inductive Coupled RFID-Systems with High Power Demand," Journal of communications, Vol. 2, No. 6, November 2007

[Riccardi 2003] Ricciardi L, Pitz I, Sarawi SFA, Varadan V, Abbott D., "Investigation into the future of RFID in biomedical applications,". Proc. of SPIE - Int. Soc Optical Eng 2003; 5119: 199-209.

[Rutherglen, 2007]

C. Rutherglen, P. Burke, "Carbon nanotube radio," Nano Lett. 7(11), 3296-3299 (2007)

[Sailor 2005] Michael J. Sailor and Jamie R. Link, Smart dust: nanostructured devices in a grain of sand, Chemical Communications, vol. 11, p. 1375, 2005

[Sani 2010] A.Sani, M.Rajab, R. Foster, Y.Hao, "Antennas and Propagation of Implanted RFIDs for Pervasive Healthcare Applications,"Proceedings of the IEEE , Vol. 98, No. 9, September 2010

[Sasaki 2007] Sasaki, S.; Seki, T.; Imanaka, K.; Kimata, M.; Toriyama, T.; Miyano, T.; Sugiyama, S.: Batteryless-Wireless MEMS Sensor System with a 3D Loop Antenna. IEEE Sensors, 2007. (Oct. 2007) $252-255$.

[Sauer 2005] Sauer C, Stanacevic M, Cauwenberghs G, Thakor N. Power harvesting and telemetry in CMOS for implanted devices. IEEE Trans Circ Sys 2005; 52(12) 2605-2613.

[Thai 2010] T. T. Thai, M. Jatlaoui, H. Aubert, P. Pons, G. R. DeJean, M. M. Tentzeris, R. Plana, "A Novel Passive Wireless Ultrasensitive Temperature RF Transducer for Remote Sensing," IEEE International Microwave Symposium (IMS), Anaheim, California, USA, May 23-28, 2010

[Thai 2010b] T.T. Thai, F. Chebila, M.M. Jatlaoui M. Mehdi, P. Pons, H. Aubert, G. R. DeJean, M. M. Tentzeris, R. Plana, "Design and Development of a Millimetre-wave Novel Passive Ultrasensitive Temperature Transducer for Remote Sensing and Identification," European Microwave Week (EuMW 2010), 26, September - 1 October 2010, Paris, France.

[Usami 2003] M. Usami, A. Sato, K. Sameshima, K. Watanabe, H.Yoshigi, R. Imura., "Powder LSI: an ultra small RF identification chip for individual recognition applications,". Solid-State Circuits Conference, 2003. Digest of Technical Papers. ISSCC. 2003 IEEE International (2003)

[Usami 2004] M. Usami, "An ultra small RFID chip: $\mu$-chip," in Radio Frequency Integrated Circuits (RFIC) Symposium, 2004. Digest of Papers. 2004 IEEE, 2004, pp. 241-244.

[Usami 2004b]

M. Usami, "An ultra small RFID chip: $\mu$-chip," 2004 LEEE Asia-Pacific Conference on Advanced System Integrated Circuits (AP-AS1C2004), Aug. 4-5.2004

[Usami 2006] M. Usami, "Ultra-Small RLID Chip Technology", 13th IEEE International Conference on Circuits and Systems (ICECS '06), pp.708-711, 2006.

[Usami 2007] M. Usami, H. Tanabe, A. Sato, I. Sakama, Y. Maki, T. Iwamatsu, T.Ipposhi, Y. Inoue., "A $0.05 \times 0.05 \mathrm{~mm} 2$ RFID Chip with Easily Scaled-Down ID-Memory," Solid-State Circuits Conference, 2007. ISSCC 2007. Digest of Technical Papers. IEEE International (2007)

[Vaillancourt 1997]

P.Vaillancourt, A. Djemouai, J. F. Harvey, and M. Sawan, "EMradiation behavior upon biological tissues in a radio-frequency power transfer link for a cortical visual implant," in Proc. IEEE EMBS Conf., vol. 6, 1997, pp. 2499-2502.

[Warneke 2001] B. Warneke, M. Last, B. Liebowitz, and K. S.J. Pister, "Smart Dust: Communicating with a Cubic-Millimeter," Computer, vol. 34, pp. 44-51, 2001.

[Warty 2008] R. Warty, M. Tofighi, U. Kawoos, and A. Rosen, "Characterization of implantable antennas for intracranial pressure monitoring: Reflection by and transmission through a scalp phantom," IEEE Trans. Microw. Theory Tech., vol. 56, no. 10, pp. 2366-2376, Oct. 2008. 